\title{
Melanin content in melanoma metastases affects the outcome of radiotherapy
}

\author{
Anna A. Brożyna ${ }^{1,2}$, Wojciech Jóźwicki1,2, Krzysztof Roszkowski³, Jan Filipiak ${ }^{4}$, \\ Andrzej T. Slominski ${ }^{5,6}$ \\ ${ }^{1}$ Department of Tumour Pathology and Pathomorphology, Oncology Centre-Prof. Franciszek Łukaszczyk Memorial Hospital, \\ Bydgoszcz, Poland \\ ${ }^{2}$ Department of Tumour Pathology and Pathomorphology, Faculty of Health Sciences, Nicolaus Copernicus University \\ Collegium Medicum in Bydgoszcz, Bydgoszcz, Poland \\ ${ }^{3}$ Department of Oncology, Radiotherapy and Gynecologic Oncology, Faculty of Health Sciences, Nicolaus Copernicus University \\ Collegium Medicum in Bydgoszcz, Bydgoszcz, Poland \\ ${ }^{4}$ Department of Chemotherapy, Oncology Centre-Prof. Franciszek Łukaszczyk Memorial Hospital, Bydgoszcz, Poland \\ ${ }^{5}$ Departments of Dermatology and Pathology, University of Alabama at Birmingham, Birmingham, AL, USA \\ ${ }^{6}$ Laboratory Service of the VA Medical Center at Birmingham, Birmingham, AL, USA
}

Correspondence to: Anna A. Brożyna, e-mail: anna.brozyna@cm.umk.pl Andrzej Slominski, e-mail: aslominski@uabmc.edu

Keywords: melanoma, melanin, survival, radiotherapy

Received: January 14, 2016

Accepted: February 11, 2016

Published: February 20, 2016

\section{ABSTRACT}

Melanin possess radioprotective and scavenging properties, and its presence can affect the behavior of melanoma cells, its surrounding environment and susceptibility to the therapy, as showed in vitro experiments. To determine whether melanin presence in melanoma affects the efficiency of radiotherapy (RTH) we evaluated the survival time after RTH treatment in metastatic melanoma patients $(n=57)$. In another cohort of melanoma patients $(n=84)$, the relationship between melanin level and $\mathrm{pT}$ and $\mathrm{pN}$ status was determined. A significantly longer survival time was found in patients with amelanotic metastatic melanomas in comparison to the melanotic ones, who were treated with either RTH or chemotherapy (CHTH) and RTH. These differences were more significant in a group of melanoma patients treated only with RTH. A detailed analysis of primary melanomas revealed that melanin levels were significantly higher in melanoma cells invading reticular dermis than the papillary dermis. A significant reduction of melanin pigmentation in PT3 and PT4 melanomas in comparison to pT1 and T2 tumors was observed. However, melanin levels measured in pT3-pT4 melanomas developing metastases (pN1-3, pM1) were higher than in pNO and pMO cases. The presence of melanin in metastatic melanoma cells decreases the outcome of radiotherapy, and melanin synthesis is related to higher disease advancement. Based on our previous cell-based and clinical research and present research we also suggest that inhibition of melanogenesis can improve radiotherapy modalities. The mechanism of relationship between melanogenesis and efficacy of RTH requires additional studies, including larger melanoma patients population and orthotopic, imageable mouse models of metastatic melanoma. 


\section{INTRODUCTION}

Cutaneous melanoma is the most rapidly increasing malignancy in the Caucasian population, and the transition from the radial growth phase (RGP) to the vertical growth phase (VGP) has an important negative impact on patient survival [1-4]. Melanomas at this stage have metastatic capability, and once the metastatic process has started, the survival rate of patients decreases dramatically [3-6]. The high mortality rate among melanoma patients, second to lung cancer, is related to its resistance to therapy during stage III and IV disease [4, 7-10].

Melanin synthesis is a metabolic pathway characteristic for melanocytes, in which L-tyrosine is transformed to heterogenous melanin biopolymer through series of oxidoreduction reactions (reviewed in [11-15]). Melanin synthesis not only serves as a diagnostic tool (e.g., differentiation marker, which allows to differentiate melanomas from other tumors) but it also affects behavior of normal and malignant melanocytes and their surrounding environment [11, 16, 17]. Specifically, melanogenesis modifies cellular metabolism, generates oxidative environment and some of its intermediates show genotoxic, mutagenic and immunosuppressive properties [11, 17-22]. Furthermore, melanin scavenges free radicals, chelates metal cations, cellular toxins including chemotherapeutics, and consumes intracellular oxygen, thus resulting in hypoxia (reviewed in [11, 13-15, 23-25]). Therefore, melanin pigment serves as a double-edge sword, which while protecting normal melanocytes from ultraviolet radiation (UVR) and oxidative stress, it can also make melanoma cells resistant to different types of therapy including chemoor radiotherapy $[11,23]$.

The above hypothesis was based on or had been substantiated by studies on experimental models of melanoma. First, several studies by investigators from Jagiellonian University have clearly demonstrated radioprotective effects of melanin pigment in physiology [26] and hamster melanoma models [27]. The decreased ability to spontaneous apoptosis in amelanotic cells, but increased sensitivity to drug-induced death when compared to pigmented cells were observed in the same experimental melanoma models, Bomirski hamster melanomas [28-31]. Furthermore, it was demonstrated that melanin synthesis attenuated the effects of radio- photo- and chemotherapy and inhibition of melanogenesis sensitized human melanoma cells to these therapeutic treatment $[21,32]$ as well as high pigmentation level was associated with melanoma resistance to treatment by vitamin D3 hydroxyderivatives [33]. Recent published data has also shown, that induction of melanogenesis is related to significant up-regulation of HIF-1 $\alpha$ and HIF-1-dependent pathways, contributing to the increased aggressiveness of melanoma [34].

Most recently, we have shown that patients at stage 3 and 4 diseases with both primary melanotic melanomas and pigmented lymph node metastases exhibited significantly shorter disease-free and overall survival time in comparison to amelanotic or poorly melanized melanomas [35]. Urbanska et al. reported positive correlation between melanization and aggressive behavior of uveal melanomas [36]. Analysis of clinical features and prognostic factors on large number of patients with uveal melanomas demonstrated that the presence of melanin was related to higher risk of metastasis and death $[37,38]$. Furthermore, we have shown that induction of melanogenesis is related to a significant up-regulation of HIF-1 $\alpha$ and HIF-1-dependent pathways [34], pathways that are recognized as the contributory to the increased aggressiveness of cancer in general $[39,40]$. Therefore, we analyzed the radiotherapy efficiency, assessed as survival time after RTH treatment in metastatic melanoma patients treated with RTH in the Oncology Centre, Prof. Franciszek Łukaszczyk Memorial Hospital, Bydgoszcz Poland during the period of 2006-2012.

\section{RESULTS}

Analysis of cohort A showed a significantly longer survival time (after RTH treatment and overall survival) of patients with amelanotic metastatic melanomas in comparison to the melanotic ones, who were treated with either RTH and CHTH or RTH (Figure 1A-1D, Table 1). These differences were more evident in the group of melanoma patients treated only with RTH (Figure 1B) in comparison to patients treated with both radio- and chemotherapy (Figure 1A) (Table 1).

Next, we determined the relationship between melanin content and $\mathrm{pT}$ and $\mathrm{pN}$ status of the tumors (Figure 2A-2H). Figure 2A shows a significant reduction of melanin pigmentation in primary $\mathrm{pT} 3$ and $\mathrm{pT} 4$ melanomas in comparison to pT1 and pT2 tumors. Further, detailed analysis revealed, however, that melanin levels were significantly higher in melanoma cells invading reticular dermis in comparison to papillary dermis (Figure 2B). Although there was no difference in melanin levels in relation to $\mathrm{pN}$ status in combined melanoma cases at $\mathrm{pT} 1$ pT4, we decided to test melanin pigmentation levels in relation to $\mathrm{pN}$ status in advanced melanomas (pT3-pT4). This substratification was dictated by our finding of higher melanin levels in deeply seated melanoma cells (Figure 2B). We found that in patients having pT3 and pT4 tumors, the mean melanin levels were significantly higher in patients with pN1-pN3 than in pN0 disease (Figure 2C). These differences were even more pronounced when melanin was analyzed in melanomas cells within the reticular dermis in comparison to the papillary dermis (Figure 2D, 2E). Subsequent analysis revealed that, melanin levels in lymph node melanoma metastases of pT4 tumors were significantly higher than those of pT2-3 tumors (Figure 2F). Similarly, pigmentation of lymph node melanoma metastases in patients with distant metastases (pM1) was also significantly higher when compared to patients with pM0 melanomas $(p=0.026$, data not shown). 


\section{DISCUSSION}

Following our previous studies on reverse relationship between melanoma melanization levels and OS and disease-free survival (DFS) in patients at stages III and IV disease [35], we analyzed the outcome of RTH in relation to pigmentation level of melanoma metastatic cells. We found that patients with amelanotic metastatic melanomas had longer survival time than pigmented ones and these differences were more pronounced in patients treated only with RTH.

These results are consistent with experimental cell culture and animal-based models showing higher resistance of pigmented melanoma cells to ionizing radiation. Already more than 50 years ago it was found that sensitivity of pigmented and amelanotic melanomas to ionizing and ultraviolet radiation differs [27, 41-43]. The significance of radioprotective features of melanin presence was further demonstrated in some hamster melanoma cell lines and hamster melanomas [36, 44-47]. Similarly, human pigmented melanoma cells exhibited higher resistance to ionizing radiation compared to non-pigmented lines $[32,48]$. Our previous research also showed, that inhibition of melanogenesis sensitized melanoma cells to ionizing radiation [32]. This results are also substantiated by studies on choroid melanomas showing that administration of melanogenesis inhibitor resulted in significant melanoma size reduction [49]. The lower susceptibility of pigmented cells to ionizing radiation than non-pigmented can result from higher oxygen consumption and/or scavenging of reactive oxygen species induced by this radiation $[27,45,46]$.

Melanogenesis, tyrosinase expression, tyrosinase activity, and the presence of melanin pigment are regarded as markers of cellular differentiation in normal and neoplastic melanocytes $[9,11,50,51]$. Recently, Sarna et al. $[52,53]$ observed inhibition of transmigration abilities of pigmented melanoma cells, accompanied by melanosomerelated decrease of its elastic properties. However in our previous studies human SkMel-188 melanoma cells cultured in media supplemented with L-tyrosine, serving
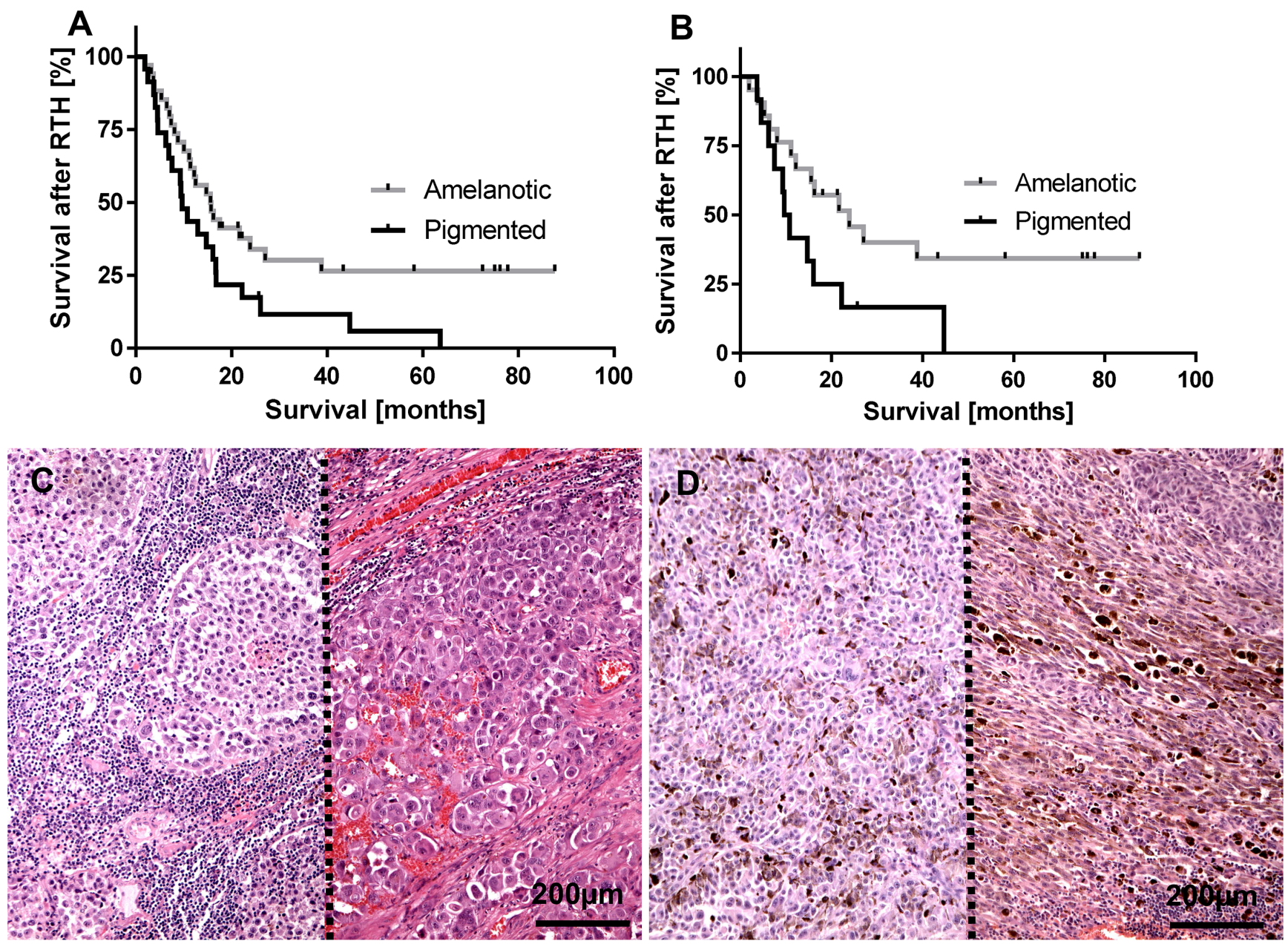

Figure 1: Survival time after radiotherapy (RTH) of all melanoma patients included into this study $\left.(\mathbf{A}), n=57 ; \chi^{2}=4.62, p=0.03\right)$ and melanoma patients received only RTH treatment $\left.(\mathbf{B}), n=33 ; \chi^{2}=4.33, p=0.04\right)$ subgrouped according melanin level in melanoma metastases. Representative lymph node melanoma metastases evaluated as amelanotic (C), two cases separated with dotted line) and pigmented (D) two cases separated with dotted line). 
Table 1: Survival after radiotherapy and overall survival in melanoma patients included in cohort A

\begin{tabular}{|c|c|c|c|c|c|}
\hline Treatment & Melanization [n] & $\begin{array}{c}\text { Survival after RTH* } \\
\text { (median/mean) } \\
{[\text { months }]}\end{array}$ & $P$ value & $\begin{array}{c}\text { OS (median/mean) } \\
\text { [months] }\end{array}$ & $P$ value \\
\hline \multirow{2}{*}{ RTH alone } & Amelanotic $[n=21]$ & $21.4 / 30.9$ & \multirow{2}{*}{0.031} & $23.6 / 51.8$ & \multirow{2}{*}{0.003} \\
\hline & Pigmented $[n=12]$ & $6.6 / 14.6$ & & $13.4 / 23.0$ & \\
\hline \multirow{2}{*}{$\begin{array}{l}\text { RTH and } \\
\text { CHTH }\end{array}$} & Amelanotic $[n=13]$ & $15.7 / 24.8$ & \multirow{2}{*}{0.043} & $37.0 / 48.1$ & \multirow{2}{*}{0.004} \\
\hline & Pigmented $[n=11]$ & $9.6 / 14.8$ & & $18.8 / 26.1$ & \\
\hline
\end{tabular}

CTHT-chemotherapy; RTH-radiotherapy; OS-overall survival time from primary diagnosis to the end of observation or death of patient, *survival time from the end of radiotherapy treatment to the end of observation or death of patient.
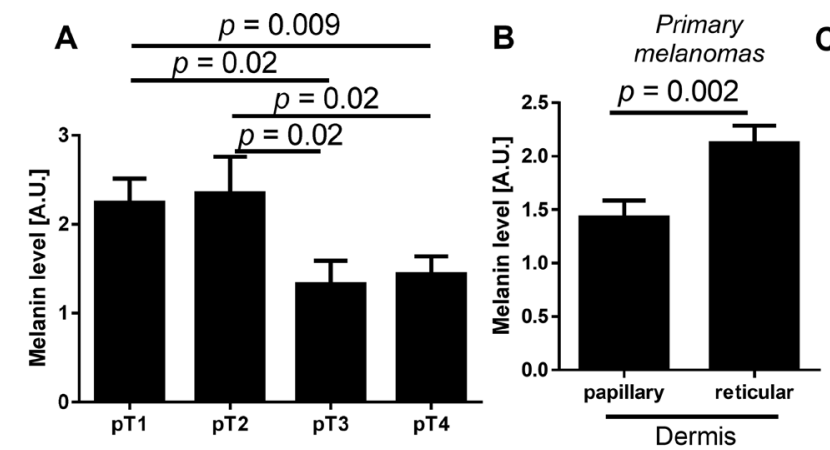

C pT3-pT4 melanomas

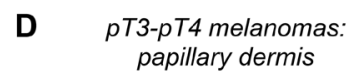

E $p T-3-p T 4$ melanomas:
reticular dermis

F Metastases
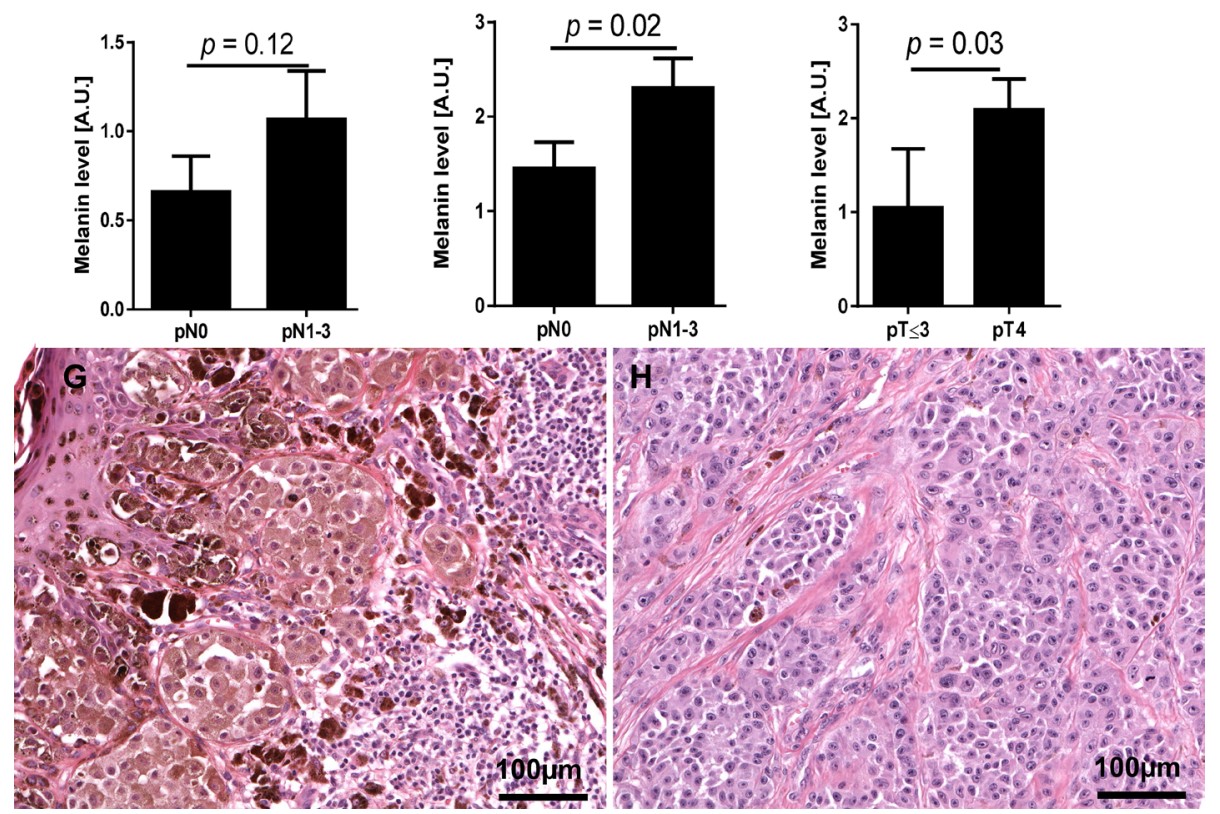

Figure 2: Mean melanin level in primary melanomas in relation to $\mathrm{pT}$ status $(\mathbf{A}) n=84)$, localization of melanoma cells in the skin (B) $n=84)$ and pN status in $\mathrm{pT} 3-\mathrm{pT} 4$ melanomas $(\mathbf{C})$. Melanin level in melanoma cells localized within papillary (D) and reticular dermis (E) of non-metastasizing (pN0) and metastasizing (pN1-3) pT3-4 melanomas $(n=45)$. Melanin level in metastases developed in pT2-3 and pT4 melanomas $(\mathbf{F})$. Representative pT1 $(\mathbf{G})$ and pT4 $(\mathbf{H})$ melanoma cases. The $p$ values represent statistical significance in MannWhitney test. 
as substrate for melanogenesis, can easily detach from the substratum in contrast to melanoma cells cultured with low L-tyrosine level (reviewed in $[22,23]$. In addition, in both human and hamster melanoma cells changes of their architecture (as round shape) were observed in pigmented cells (reviewed in [22, 23]). These changes can increase the metastatic potential of melanoma cells. Interestingly, in the present study, melanin level in primary tumors melanomas was highest in pT1-pT2 tumors and decreased with increasing melanoma advancement defined as $\mathrm{pT}$ stage. However, detailed analysis showed that this tendency diverted when we analyzed only pT3-pT4 melanomas in which melanin level increased with development of metastases. This analysis also showed that melanin in primary tumors was more abundant in deeply located melanoma cells, and in advanced melanomas the highest pigmentation was observed in melanomas that developed regional and distant metastases. Similarly, most pigmented metastases were observed in pT4 tumors. This could reflect the acquiring more malignant phenotype and/or defense of melanoma cells against applied therapy. Previously we have observed shortened OS and DFS of III and IV stage melanoma patients in highly pigmented primary melanomas and metastases [35] that is consistent with the above observations. This is further substantiated by a positive correlation between melanin pigment and higher probability of metastasis or death in uveal melanomas [37, 38].

The shorter survival time of patients with pigmented metastatic melanomas than with amelanotic ones probably results from the melanin- and melanogenesis-related decrease in efficacy of RTH. Melanin and melanogenesis scavenging of reactive oxygen species and generating the hypoxic conditions $[14,27,45,46]$ and hypoxia in tumors can attenuate efficiency of the RTH (reviewed in [54]). This concept is also substantiated by our studies showing that melanogenesis activates hypoxia-induced molecular pathways via up-regulation of HIF- $1 \alpha$ and HIF-1-regulated genes [34] and is consistent with previous studies showing that stimulation or induction of melanogenesis can stimulate anaerobic glycolysis [55, 56] and pentose phosphate pathway $[57,58]$. This concept need to be confirmed in larger melanoma population. Furthermore, the mechanism of the higher efficacy of RTH in amelanotic human melanomas deserves further detailed studies using appropriate animal models. These are represented by patient-derived orthotopic xenografts, which reproduce clinical tumor growth and metastasis, or melanoma models labelled by fluorescent probes allowing monitoring of tumor behavior in real time [59-62]. These models could also be used as indicators of individual patient susceptibility to RTH.

In conclusion, the presence of melanin in metastatic melanoma cells attenuates efficacy of radiotherapy. Thus, the inhibition of melanogenesis could sensitize melanoma cells and improve the outcome of radiotherapy in melanoma patients.

\section{PATIENTS AND METHODS}

This study was approved by the Committee of Ethics of Scientific Research of Collegium Medicum of Nicolaus Copernicus University, Poland.

\section{Patients}

Two cohorts of melanoma patients that were diagnosed and treated at the Oncology Center in Bydgoszcz, Poland were analyzed in relation to the clinicopathological characteristics listed in Table 2. Cohort A represented 57 patients with melanized and amelanotic metastatic melanomas that were confirmed histologically, and who received radiotherapy. Thirty-three patients received only radiotherapy, while 24 received both RTH and CHTH (Table 2, column Cohort A). The metastatic melanomas in 48 out of 57 patients were removed by surgery just before RTH. In 7 patients metastatic tumors were resected 8-18 months before RTH. These patients received CHTH followed by RTH. In 2 patients, RTH followed diagnosis of metastatic tumors by core biopsy.

Patients were treated by RTH with 6-MeV photons for a total dose of the hypofractionated regimen of $30 \mathrm{~Gy}$ in five fractions of $6 \mathrm{~Gy}$ per fraction delivered twice weekly (Monday and Thursday or Tuesday and Friday). The Planning Target Volume (PTV) was used for metastases in cervical nodes with any of the following: extranodal disease, more than one lymph node involved, any lymph node with largest dimension greater than $2 \mathrm{~cm}$, or recurrent disease in a previous neck dissection.

For axillary node metastases, PTV was used when there was extranodal disease, at least four lymph nodes were involved, and their nodal size was at least $3 \mathrm{~cm}$, or the disease was recurrent in a previously dissected axilla. The RTH treatment was strictly focused on the axilla and the supraclavicular fossa was not targeted, unless special instructions existed to include that region. Anterior and posterior photon fields were used with appropriate wedges or compensation filters that minimize heterogeneity in radiation dose caused by surface or separation irregularities.

Radiation-field targets for inguinal node metastases was generally less comprehensive than the targets for the cervical and axillary regions, to minimize the risk of morbid lymphedema. Fields were targeted to the regions that were clinically involved with disease and did not include subclinical disease in the external or common iliac nodal chains unless there was an obvious clinical involvement before dissection.

Cohort B consisted of 84 melanoma patients with primary cutaneous with or without metastatic disease (Table 2, cohort B). In this group, melanomas were diagnosed in Oncology Centre in Bydgoszcz and previously analyzed for relationship between melanin 
Table 2: Clinico-pathological characterization of the melanoma patients treated with radiotherapy

\begin{tabular}{|c|c|c|}
\hline Features & Cohort A & Cohort B \\
\hline Age (yrs) & $56.0(25.7-83.6)$ & $59.0(22-100)$ \\
\hline $\begin{array}{c}\text { Gender } \\
\mathrm{F} \\
\mathrm{M}\end{array}$ & $\begin{array}{l}22 \\
35\end{array}$ & $\begin{array}{l}41 \\
43\end{array}$ \\
\hline $\begin{array}{l}\text { Therapy } \\
\text { Only surgery } \\
\text { Only CHTH } \\
\text { Only RTH } \\
\text { RTH and CHTH }\end{array}$ & $\begin{array}{c}0 \\
0 \\
33 \\
24\end{array}$ & $\begin{array}{c}53 \\
9 \\
11 \\
11\end{array}$ \\
\hline $\begin{array}{l}\text { Melanization } \\
\text { Amelanotic } \\
\text { Melanin level 0 } \\
\text { Melanin level 1f } \\
\text { Pigmented } \\
\text { Melanin level 1d } \\
\text { Melanin level 2 } \\
\text { Melanin level } 3 \\
\text { Melanin level } 4 \\
\text { Melanin level 5 }\end{array}$ & $\begin{array}{c}\text { Metastatic melanomas } \\
34 \\
25 \\
9 \\
23 \\
3 \\
5 \\
4 \\
2 \\
9\end{array}$ & $\begin{array}{c}\text { Primary/metastatic melanomas } \\
35 / 15 \\
20 / 15 \\
15 / 0 \\
49 / 18 \\
5 / 4 \\
15 / 3 \\
14 / 2 \\
14 / 4 \\
1 / 5\end{array}$ \\
\hline $\begin{array}{l}\text { pT } \\
\text { pT1 } \\
\text { pT2 } \\
\text { pT3 } \\
\text { pT4 }\end{array}$ & $\begin{array}{l}-* \\
-* \\
-* \\
-*\end{array}$ & $\begin{array}{l}29 \\
10 \\
13 \\
32\end{array}$ \\
\hline $\begin{array}{l}\mathrm{pN} \\
\mathrm{pN} 0 \\
\mathrm{pN} 1 \\
\mathrm{pN} 2 \\
\mathrm{pN} 3\end{array}$ & $\begin{array}{l}-* \\
-* \\
-* \\
-*\end{array}$ & $\begin{array}{c}57 \\
11 \\
11 \\
5\end{array}$ \\
\hline
\end{tabular}

CTHT-chemotherapy; RTH-radiotherapy; 1f - melanin content defined as 1 but with focal distribution; 1d - melanin content defined as 1 but with dispersed distribution

*- the data related to $\mathrm{pT}$ and $\mathrm{pN}$ status of patients in cohort A qualified for RTH treatment are incomplete since $68 \%$ of primary lesions were diagnosed in other hospitals and histopathological examination reports were not accessible

\#- number of metastases includes both melanoma metastases resected at the time of primary diagnosis $(n=27)$ and during the follow-up $(n=6)$.

content and overall or disease free survival times [35]. In this study, a detailed evaluation was performed to determine the relationship between melanin level in the tumor and $\mathrm{pT}$ and $\mathrm{pN}$ status.

\section{Melanin evaluation}

Assessment of relative melanin content in melanomas was based on the evaluation of diagnostic $\mathrm{H} \& \mathrm{E}$ stained 
slides following protocols described previously [35]. Briefly, the relative scale was defined as the percentage presence of melanin in the melanoma cells of the analyzed tumor sections: 0 -melanin was absent, $1-$ melanin was present in $\leq 10 \%$ of melanoma cells, $2-$ melanin was present in $11-$ $25 \%$ of melanoma cells, $3-$ melanin was present in $26-50 \%$ of melanoma cells, 4-melanin was present $51-75 \%$ of melanoma cells, and 5-melanin was present in $>75 \%$ of melanoma cells (Figure 3A-3F). The spatial distribution of melanin was assessed as scattered when melanized melanoma cells were dispersed within tumors or as focal when melanized melanoma cells were grouped together in one or more foci. Melanomas without melanin (Figure 3A) or with melanin content defined as 1 but with focal distribution were grouped as amelanotic. Melanomas with melanin content defined as 2-5 (Figure 3C-3F) and melanomas with melanin content defined as 1 but with dispersed distribution (3B) were qualified as pigmented. In cohort $\mathrm{A}$, melanin content was assessed in metastatic melanoma cells. In cohort B, melanin content was evaluated both in metastatic and primary melanomas. In the latter melanin content was evaluated separately in papillary and reticular dermis.

\section{Statistical analysis}

Survival time analyses were performed using the log-rank test. Both survival time after RTH treatment (defined as the period from the end of RTH to the date of death/the end of observation) and overall survival time (defined as time from patomorphologic diagnosis of primary melanoma and date of death/the end of observation) were analyzed. The mean melanin level in analyzed subgroups of cases (stratified according pT, $\mathrm{pN}, \mathrm{pM}$ and localization of melanoma cells within skin) was compared using Mann-Whitney test. Differences between mean/median survival times were analyzed using the Student $t$-test. All statistical analyses were performed using Prism 5.0 (GraphPad Software, San Diego, CA).
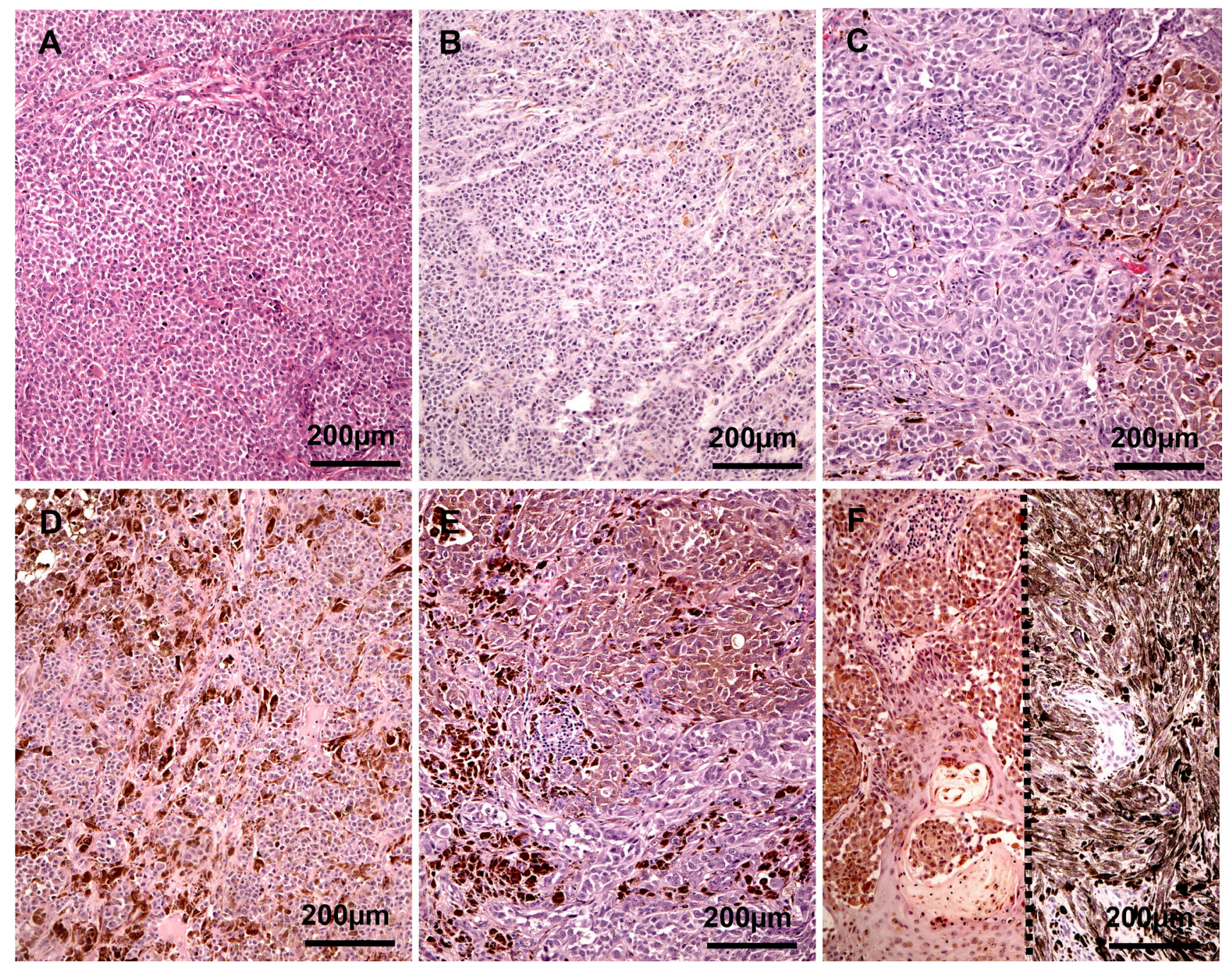

Figure 3: Representative melanoma cases evaluated as amelanotic (A), melanin 1 (B), 2 (C), 3 (D), 4 (E) and 5 (F) two cases separated with dotted line). 


\section{FINANCIAL SUPPORT}

The work was supported by grant 2014/15/B/ NZ4/00751 from National Science Centre, Poland (AAB) and $\mathrm{CO} / \mathrm{ZPNiP} / 1 / 2013$ from Oncology Centre-Prof. Franciszek Łukaszczyk Memorial Hospital (AAB) and by NIH grant 1R01AR056666-01A2 (ATS).

\section{CONFLICTS OF INTEREST}

Authors declare no conflicts of interest.

\section{REFERENCES}

1. Elder DE. Pathological staging of melanoma. Methods Mol Biol. 2014; 1102:325-351.

2. Linos K, Slominski A, Ross JS, Carlson JA. Melanoma update: diagnostic and prognostic factors that can effectively shape and personalize management. Biomark Med. 2011; 5:333-360.

3. Carlson JA, Ross JS, Slominski A, Linette G, Mysliborski J, Hill J, Mihm M, Jr. Molecular diagnostics in melanoma. J Am Acad Dermatol. 2005; 52:743-775; quiz 775-748.

4 . Miller AJ, Mihm MC, Jr. Melanoma. N Engl J Med. 2006; 355:51-65.

5. Gimotty PA, Guerry D, Ming ME, Elenitsas R, Xu X, Czerniecki B, Spitz F, Schuchter L, Elder D. Thin primary cutaneous malignant melanoma: a prognostic tree for 10-year metastasis is more accurate than American Joint Committee on Cancer staging. J Clin Oncol. 2004; 22:3668-3676.

6. Guerry Dt, Synnestvedt M, Elder DE, Schultz D. Lessons from tumor progression: the invasive radial growth phase of melanoma is common, incapable of metastasis, and indolent. J Invest Dermatol. 1993; 100:342S-345S.

7. Nikolaou V, Stratigos AJ. Emerging trends in the epidemiology of melanoma. Br J Dermatol. 2014; 170:11-19.

8. Slominski AT, Carlson JA. Melanoma resistance: a bright future for academicians and a challenge for patient advocates. Mayo Clin Proc. 2014; 89:429-433.

9. Slominski A, Wortsman J, Carlson AJ, Matsuoka LY, Balch CM, Mihm MC. Malignant melanoma. Arch Pathol Lab Med. 2001; 125:1295-1306.

10. Linette GP, Carlson JA, Slominski A, Mihm MC, Ross JS. Biomarkers in melanoma: stage III and IV disease. Expert Rev Mol Diagn. 2005; 5:65-74.

11. Slominski A, Tobin DJ, Shibahara S, Wortsman J. Melanin pigmentation in mammalian skin and its hormonal regulation. Physiol Rev. 2004; 84:1155-1228.

12. Prota G: Melanins and Melanogenesis. San Diegoo, New York, Boston, London, Sydney, Tokyo, Toronto Academic Press, Inc. Harcourt Brace Jovanovich, Publishers; 1992.

13. Prota G. Melanins, melanogenesis and melanocytes: looking at their functional significance from the chemist's viewpoint. Pigment Cell Res. 2000; 13:283-293.
14. Meredith P, Sarna T. The physical and chemical properties of eumelanin. Pigment Cell Res. 2006; 19:572-594.

15. Sarna T. Properties and function of the ocular melanin--a photobiophysical view. J Photochem Photobiol B. 1992; 12:215-258.

16. Slominski A, Wortsman J, Carlson A, Matsuoka L, Balch CM, Mihm M. Malignant melanoma: An update. Arch Pathol Lab Med. 2001; 125:1295-1306.

17. Slominski A, Paus R, Mihm MC. Inhibition of melanogenesis as an adjuvant strategy in the treatment of melanotic melanomas: selective review and hypothesis. Anticancer Res. 1998; 18:3709-3715.

18. Lazova R, Pawelek JM. Why do melanomas get so dark? Exp Dermatol. 2009; 18:934-938.

19. Meyskens FL, Jr., Farmer PJ, Yang S, Anton-Culver H. New perspectives on melanoma pathogenesis and chemoprevention. Recent Results Cancer Res. 2007; 174:191-195.

20. Plonka PM, Passeron T, Brenner M, Tobin DJ, Shibahara S, Thomas A, Slominski A, Kadekaro AL, Hershkovitz D, Peters E, Nordlund JJ, Abdel-Malek Z, Takeda K et al. What are melanocytes really doing all day long...? Exp Dermatol. 2009; 18:799-819.

21. Slominski A, Zbytek B, Slominski R. Inhibitors of melanogenesis increase toxicity of cyclophosphamide and lymphocytes against melanoma cells. Int J Cancer. 2009; 124:1470-1477.

22. Slominski A, Zmijewski MA, Pawelek J. L-tyrosine and L-dihydroxyphenylalanine as hormone-like regulators of melanocyte functions. Pigment Cell Melanoma Res. 2012; 25:14-27.

23. Slominski RM, Zmijewski MA, Slominski AT. The role of melanin pigment in melanoma. Exp Dermatol. 2015; 24:258-259.

24. d'Ischia M, Wakamatsu K, Cicoira F, Di Mauro E, GarciaBorron JC, Commo S, Galvan I, Ghanem G, Kenzo K, Meredith P, Pezzella A, Santato C, Sarna T et al. Melanins and melanogenesis: from pigment cells to human health and technological applications. Pigment Cell Melanoma Res. 2015; 28:520-544.

25. Schweitzer AD, Howell RC, Jiang Z, Bryan RA, Gerfen G, Chen CC, Mah D, Cahill S, Casadevall A, Dadachova E. Physico-chemical evaluation of rationally designed melanins as novel nature-inspired radioprotectors. PLoS One. 2009; 4:e7229.

26. Lukiewicz S. The biological role of melanin. I. New concepts and methodical approaches. Folia Histochem Cytochem (Krakow). 1972; 10:93-108.

27. Pajak S, Subczynski W, Panz T, Lukiewicz S. Rate of oxygen consumption of hamster melanoma cells as a factor influencing their radioresistance. Folia Histochem Cytochem (Krakow). 1980; 18:33-39.

28. Cichorek M. Camptothecin-induced death of amelanotic and melanotic melanoma cells in different phases of cell cycle. Neoplasma. 2011; 58:227-234. 
29. Cichorek M, Kozlowska K, Bryl E. The activity of caspases in spontaneous and camptothecin-induced death of melanotic and amelanotic melanoma cell. Cancer Biol Ther. 2007; 6:346-353.

30. Lukiewicz S, Pilas B, Nowicka J, Cieszka K, Gurbiel R. Molecular and Cellular Basis of Different Radiosensitivity in Pigmented and Non-Pigmented Hamster Melanoma Cells. The Yale Journal of Biology and Medicine (The XI International Pigment Cell Conference). 1980; 53:391-392.

31. Lukiewicz S, Mach H, Link E, Maciejewski Z, Pilas B, Nowicka J. Laboratory Tests and Clinical Trials on Chemical Radiosensitization of Pigmented Cells (Including Hamster and Human Melanoma). The Yale Journal of Biology and Medicine (The XI International Pigment Cell Conference). 1980; 53:392.

32. Brozyna AA, VanMiddlesworth L, Slominski AT. Inhibition of melanogenesis as a radiation sensitizer for melanoma therapy. Int J Cancer. 2008; 123:1448-1456.

33. Janjetovic Z, Brozyna AA, Tuckey RC, Kim TK, Nguyen MN, Jozwicki W, Pfeffer SR, Pfeffer LM, Slominski AT. High basal NF-kappaB activity in nonpigmented melanoma cells is associated with an enhanced sensitivity to vitamin D3 derivatives. Br J Cancer. 2010; 105:1874-1884.

34. Slominski A, Kim TK, Brozyna AA, Janjetovic Z, Brooks DL, Schwab LP, Skobowiat C, Jozwicki W, Seagroves TN. The role of melanogenesis in regulation of melanoma behavior: melanogenesis leads to stimulation of HIF-1alpha expression and HIF-dependent attendant pathways. Arch Biochem Biophys. 2014; 563:79-93.

35. Brozyna AA, Jozwicki W, Carlson JA, Slominski AT. Melanogenesis affects overall and disease-free survival in patients with stage III and IV melanoma. Hum Pathol. 2013; 44:2071-2074.

36. Urbanska K, Romanowska-Dixon B, Elas M, Pajak S, Paziewski E, Bryk J, Kukielczak B, Slominski A, ZygulskaMach H, Lukiewicz S. Experimental ruthenium plaque therapy of amelanotic and melanotic melanomas in the hamster eye. Melanoma Res. 2000; 10:26-35.

37. Shields CL, Kaliki S, Cohen MN, Shields PW, Furuta M, Shields JA. Prognosis of uveal melanoma based on race in 8100 patients: The 2015 Doyne Lecture. Eye (Lond). 2015; 29:1027-1035.

38. Shields CL, Kaliki S, Furuta M, Fulco E, Alarcon C, Shields JA. American Joint Committee on Cancer Classification of Uveal Melanoma (Anatomic Stage) Predicts Prognosis in 7,731 Patients: The 2013 Zimmerman Lecture. Ophthalmology. 2015; 122:1180-1186.

39. Chiche J, Ricci JE, Pouyssegur J. Tumor hypoxia and metabolism-towards novel anticancer approaches. Ann Endocrinol (Paris). 2013; 74:111-114.

40. Maynard MA, Ohh M. The role of hypoxia-inducible factors in cancer. Cell Mol Life Sci. 2007; 64:2170-2180.
41. Chalmers AH, Lavin M, Atisoontornkul S, Mansbridge J, Kidson C. Resistance of human melanoma cells to ultraviolet radiation. Cancer Res. 1976; 36:1930-1934.

42. Cobb JP. Effect of in vitro $\mathrm{X}$ irradiation on pigmented and pale slices of Cloudman S91 mouse melanoma as measured by subsequent proliferation in vivo. J Natl Cancer Inst. 1956; 17:657-666.

43. Hopwood LE, Swartz HM, Pajak S. Effect of melanin on radiation response of $\mathrm{CHO}$ cells. Int J Radiat Biol Relat Stud Phys Chem Med. 1985; 47:531-537.

44. Mileo AM, Mattei E, Fanuele M, Delpino A, Ferrini U. Differential radiosensitivity in cultured B-16 melanoma cells following interrupted melanogenesis induced by glucosamine. Pigment Cell Res. 1989; 2:167-170.

45. Lukiewcz S: Interference with endogenous radioprotectors as a method of radiosensitization in "IAEA's Modification of Radiosensitivity of Biological Systems". In: Proceedings of the Advisory Group Meeting on Modification of Radiosensitivity of Biological Systems, International Atomic Energy Agency. December 8-11, 1975, Vienna, Austria; 1976:61-76.

46. Lukiewcz S: Electron spin resonance studies on the detectability of radiation damage and radiosensitization of neoplastic cells in "IAEA's Improvement in Radiotherapy of Cancer Using Modifier of Radiosensitivity of Cells". In: Final Research Coordinantion Meeting, International Atomic Energy Agency. January, Julich, Germany; 1982:1-10.

47. Kukielczak B, Romanowska B, Bryk J. Gamma radiation and MC540 photosensitization of melanoma in the hamster's eye. Melanoma Res. 1999; 9:115-124.

48. Kinnaert E, Morandini R, Simon S, Hill HZ, Ghanem G, Van Houtte P. The degree of pigmentation modulates the radiosensitivity of human melanoma cells. Radiat Res. 2000; 154:497-502.

49. Zygulska-Mach H, Maciejewski Z, Lukiewicz S, Iwasiow B, Link E. Clinical trials on chemical radiosensitization of malignant melanoma of the choroid. Ophthalmologica. 1979; 178:194-197.

50. Bellei B, Flori E, Izzo E, Maresca V, Picardo M. GSK3beta inhibition promotes melanogenesis in mouse B16 melanoma cells and normal human melanocytes. Cell Signal. 2008; 20:1750-1761.

51. Laughlin KM, Luo D, Liu C, Shaw G, Warrington KH, Jr., Law BK, Harrison JK. Hematopoietic- and neurologicexpressed sequence $1(\mathrm{Hn} 1)$ depletion in B16.F10 melanoma cells promotes a differentiated phenotype that includes increased melanogenesis and cell cycle arrest. Differentiation. 2009; 78:35-44.

52. Sarna M, Zadlo A, Pilat A, Olchawa M, Gkogkolou P, Burda K, Bohm M, Sarna T. Nanomechanical analysis of pigmented human melanoma cells. Pigment Cell Melanoma Res. 2013; 26:727-730. 
53. Sarna M, Zadlo A, Hermanowicz P, Madeja Z, Burda K, Sarna T. Cell elasticity is an important indicator of the metastatic phenotype of melanoma cells. Exp Dermatol. 2014; 23:813-818.

54. Rockwell S, Dobrucki IT, Kim EY, Marrison ST, Vu VT. Hypoxia and radiation therapy: past history, ongoing research, and future promise. Curr Mol Med. 2009; 9:442-458.

55. Scislowski PW, Slominski A, Bomirski A. Biochemical characterization of three hamster melanoma variants - II. Glycolysis and oxygen consumption. Int J Biochem. 1984; 16: 327-331.

56. Li W, Slominski R, Slominski AT. High-resolution magic angle spinning nuclear magnetic resonance analysis of metabolic changes in melanoma cells after induction of melanogenesis. Anal Biochem. 2009; 386:282-284.

57. Scislowski PW, Slominski A. The role of NADP-dependent dehydrogenases in hydroxylation of tyrosine in hamster melanoma. Neoplasma. 1983; 30:239-243.
58. Scislowski PW, Slominski A, Bomirski A, Zydowo M. Metabolic characterization of three hamster melanoma variants. Neoplasma. 1985; 32:593-598.

59. Hoffman RM. Patient-derived orthotopic xenografts: better mimic of metastasis than subcutaneous xenografts. Nat Rev Cancer. 2015; 15:451-452.

60. Hoffman RM. Orthotopic metastatic mouse models for anticancer drug discovery and evaluation: a bridge to the clinic. Invest New Drugs. 1999; 17:343-359.

61. Yang M, Jiang P, An Z, Baranov E, Li L, Hasegawa S, Al-Tuwaijri M, Chishima T, Shimada H, Moossa AR, Hoffman RM. Genetically fluorescent melanoma bone and organ metastasis models. Clin Cancer Res. 1999; 5: 3549-3559.

62. Hoffman RM. The multiple uses of fluorescent proteins to visualize cancer in vivo. Nat Rev Cancer. 2005; 5:796-806. 